\title{
High-frequency directivity effects: evidence from analysis of the Les Saintes records
}

\author{
Y. Chen • J. Letort • F. Cotton • S. Drouet
}

Received: 3 July 2013 / Accepted: 28 January 2014 / Published online: 13 February 2014

(C) The Author(s) 2014. This article is published with open access at Springerlink.com

\begin{abstract}
The main-shock (Mw, 6.3) and the aftershocks of the 'Les Saintes' earthquake sequence (French Indies) were analyzed to quantify highfrequency directivity effects. A correction method was applied to isolate source spectra within a large frequency range ( 0.5 to $25 \mathrm{~Hz}$ ). Most of the aftershocks source spectra are fully consistent with a Brune spectrum pointsource shape and do not show any azimuthal dependence. The main-shock (Mw, 6.3) and the two largest aftershocks (Mw, 5.8, 5.3) show, however, a clear azimuthal dependence that indicates significant directivity effect. The discrepancy of the radiated spectral energy and the change in the corner frequencies introduced by directivity effects show that such an effect is significant at high frequency (from 1 to $25 \mathrm{~Hz}$ ). Our data suggest that the amplitudes in the main-shock Fourier spectrum at directive sites are around a factor of 2.5 higher with respect to anti-directive sites.
\end{abstract}

Y. Chen $\cdot$ J. Letort $\cdot$ F. Cotton

ISTerre, University Joseph Fourier,CNRS, BP 53, 38041 Grenoble Cedex 9, France

Y. Chen $(\bowtie)$

UME School, Istituto Universitario di Studi Superiori di Pavia, Via Ferrata 1, 27100 Pavia, Italy

e-mail: yenshin.chen@iusspavia.it

S. Drouet

Observatório Nacional, Rua General Jose Cristino 77, São

Cristovão, Rio de Janeiro, Brazil
Keywords Ground-motion · French Indies · Directivity effect · Seismic hazard

\section{Introduction}

Finite-source effects such as low-frequency directivity effects have been well known for decades (Haskell 1964; Boore and Joyner 1989; Somerville et al. 1997; Seekins and Boatwright 2010). However, highfrequency (above 1 to $2 \mathrm{~Hz}$ ) directivity remains an open debate (Boatwright 2007; Cultrera et al. 2009). The controversy concerning whether directivity has a relevant impact on high frequencies is widely discussed, including the theoretical considerations that support opposite opinions: While some studies claim that steadystate rupture propagation would enhance directivity effects by the assumption of quasi-deterministic rupture behavior (Boore and Joyner 1989; Gallovic and Burjanek 2007; Ruiz et al. 2011), other studies claim that incoherencies in the rupture, because subevents are located randomly on the fault plane with random microscale rupture directivity (stochastic rupture behavior), might strongly attenuate directivity effects (Bernard and Herrero 1994; Somerville et al. 1997; Boatwright et al. 2002; Spudich and Chiou 2008; Ameri et al. 2012; Ruiz et al. 2011). From an observational perspective, Boatwright et al. (2002) evaluated the variation in the corrected velocity spectra with the azimuth, and observed directivity up to $1 \mathrm{~Hz}$. Ameri et al. (2012) suggested directivity effects observed up to $2 \mathrm{~Hz}$ at very 
close stations for strong ground motions recorded during the Mw 6.3 2009 L'Aquila earthquake.

Several fundamental earthquake properties can be measured from the spectral content of seismic-wave arrivals. For example, directivity effects cause variations in the height of the spectra plateau, as the earthquake energy will focus along the rupture direction (Gallovic and Burjanek 2007), as well as a shift in the spectral corner frequency (Boore and Joyner 1989) and the duration of the apparent source-time function is shorter than the non-directive sites. Figure $\mathrm{C} 1$ in Ruiz et al. (2011) demonstrates clearly how the acceleration source spectra are expected to change for directive and antidirective sites under different assumptions at high frequency. Under quasi-deterministic rupture behavior assumption, the expected spectral plateau is the highest at directive site and the lowest at anti-directive site. On the contrary, under stochastic rupture behavior condition, the spectral plateaus are merged together at high frequency from a theoretical perspective. However, because of the variety of masking mechanisms, such as sourcereceiver path effects (which include the effects of geometric spreading and anelastic attenuation along the ray path), and because of the station site responses, earthquake source spectra are inaccessible to direct observation (Boore and Joyner 1989). The general lack of data covering the whole focal sphere also results in ambiguous observational evidence for the effects of directivity.

On November 21, 2004, at 11:41 UTC, a magnitude Mw 6.3 earthquake (Harvard Global Centroid Moment Tensor Catalog http://www.globalcmt.org/CMTsearch. html) struck offshore (10 km south) of the 'Les Saintes' islands in Guadeloupe, French West Indies (Fig. 1). There were more than 30,000 aftershocks recorded over the following years, most of which occurred at shallow depths near the islands of the archipelago. The main-shock and its aftershocks were recorded by the French Accelerometric Network stations, plus the accelerometric stations of the 'Conseil Général de Martinique'. All the accelerometric data are freely available at http://www-rap.obs.ujf-grenoble.fr/ (Péquegnat et al. 2008).

The resulting high-quality dataset provides a good opportunity to access information on earthquake sources, regional attenuation, and local site effects. The recent study of Drouet et al. (2011) provided updated regional attenuation relationships and amplification factors of the accelerometric stations in this area. Through this new information, we have been able to analyze the corrected source spectra of the Les Saintes earthquake sequence and to evaluate how the source affects control of the observed spectra. Based on the main-shock study of Feuillet et al. (2011), accelerometric stations are either located in directive sites (Guadeloupe) or anti-directive sites (Martinique), and this suitable station coverage allows us to analyze the azimuthal dependency of the radiated energy.

Our research strategy is straightforward. We first computed the corrected source spectra by removing path and site effects. Secondly, as the source spectra can be affected by the combined effects of radiation pattern effects and directivity effects, we removed potential radiation pattern effects. Finally, we compared and analyzed the high-frequency azimuthal dependency of the Fourier spectra of the main-shock and all of the aftershock sequence earthquakes characterized by $\mathrm{Mw}>5$ and high-quality recordings for both directive and antidirective sites (Table 1).

\section{Analysis of propagation and site-corrected spectra: evidence of a source-directivity effect?}

The ability to compute isolated source spectra by removing path and site effects is a key prior need for the detection of high-frequency directivity effects. Given the shape of the Brune spectrum, acceleration spectra are more sensitive to high-frequencies $(\mathrm{f}>1 \mathrm{~Hz})$ directivity effects. Thus, we computed and analyzed the average $S$-wave acceleration Fourier spectra from the Les Saintes earthquake sequence.

Each observed $S$-wave acceleration Fourier spectrum from source $i$ and receiver $j$ is a product of the source term, the regional propagation path effect, and the local site transfer function, as shown in Eq. (1):

$A_{\mathrm{ijk}}\left(r_{\mathrm{ij}}, f_{\mathrm{k}}\right)=\Omega_{\mathrm{i}}\left(\mathrm{f}_{\mathrm{k}}\right) \mathrm{D}_{\mathrm{ij}}\left(\mathrm{r}_{\mathrm{ij}}, \mathrm{f}_{\mathrm{k}}\right) \mathrm{S}_{\mathrm{j}}\left(\mathrm{f}_{\mathrm{k}}\right)$

Where, $A_{\mathrm{ijk}}\left(r_{\mathrm{ij} j} f_{\mathrm{k}}\right)$ is the acceleration Fourier spectra observed from source $i$ at receiver $j$, for a given frequency $f_{k}$. The source term is described using the Brune's source model, as shown in Eq. (2):

$\Omega_{i}\left(f_{k}\right) \sim \frac{\left(2 \pi f_{k}\right)^{2} M_{o_{j}}}{\left[1+\left(\frac{f_{k}}{f_{c_{i}}}\right)^{2}\right]}$

where, $M_{0_{i}}$ is the seismic moment, and $f_{c_{i}}$ is the corner frequency of event $i$. 


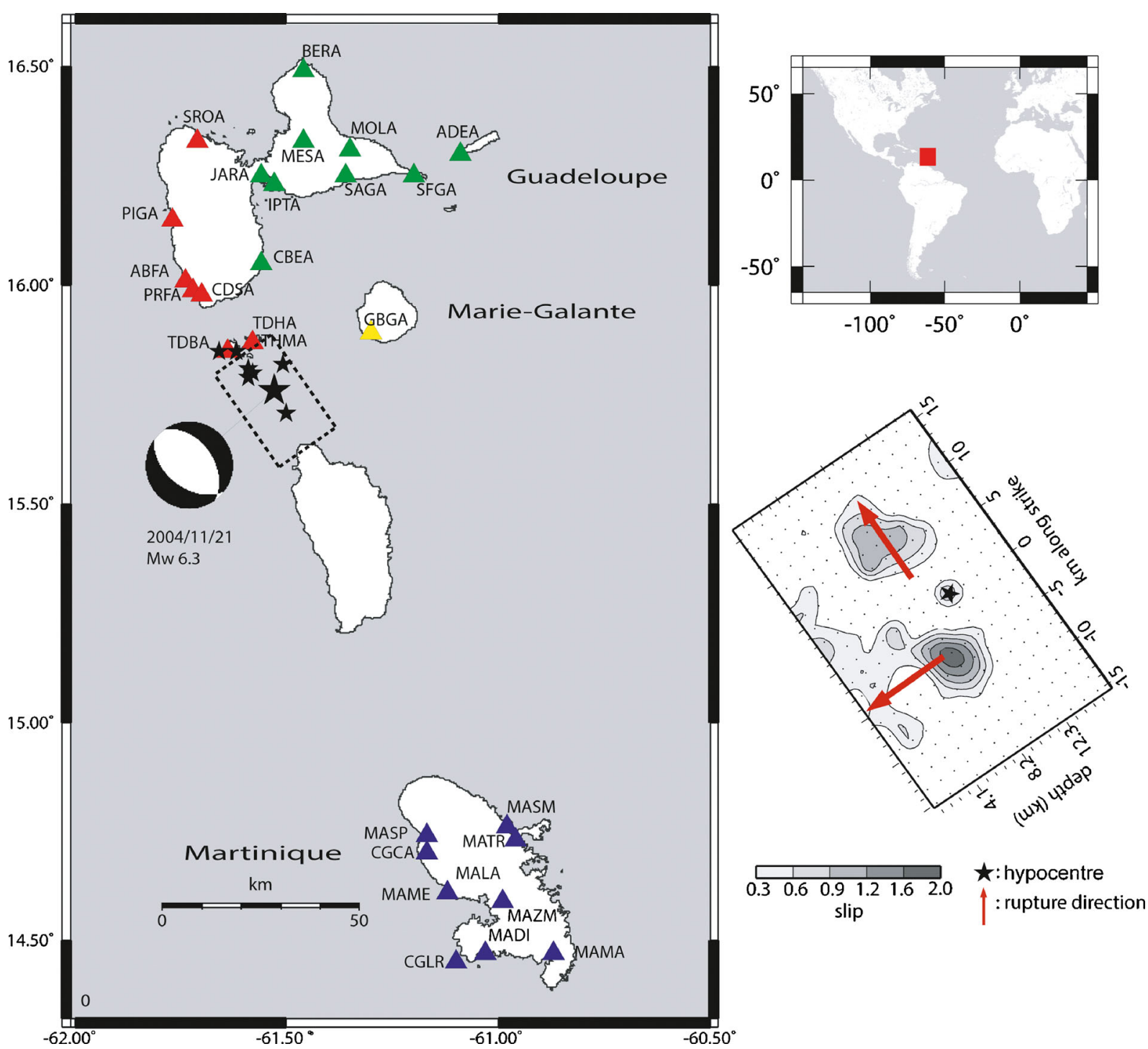

Fig. 1 Map showing the earthquakes (black stars), seismic stations (triangles), and the main-shock focal mechanism. Also shown are a map of the location of the study area (top right, red square) and the main-shock co-seismic slip model (bottom right). On the main map, the location of the main-shock on November 21, 2004, at 11:41 UTC, is shown by the largest black star, and the co-seismic slip plan is indicated by the dashed black square. The red arrows on the slip distribution diagram show the rupture direction of the two patches suggested by Feuillet et al.

The attenuation along the ray path $r_{i j}$ includes the effects of geometric spreading and anelastic attenuation, as shown in Eq. (3):

$D_{\mathrm{ij}}\left(r_{\mathrm{ij}}, f_{\mathrm{k}}\right)=\exp \left(-\frac{\pi \mathrm{r}_{\mathrm{ij}} \mathrm{f}_{\mathrm{k}}}{Q\left(\mathrm{f}_{\mathrm{K}}\right) v_{\mathrm{s}}}\right) \times \frac{1}{\mathrm{r}_{\mathrm{ij}}^{\gamma}}$
(2011), Drouet et al. (2011), and the observation shown in our study. The station classification is done according to the angle between the strike of the main-shock fault orientation, as given by Feuillet et al. (2011), and the source-tostation direction. Red stations, $<30^{\circ}$ (western Guadeloupe Island); green stations, from $30^{\circ}$ to $75^{\circ}$ (eastern Guadeloupe Island); yellow stations, azimuth perpendicular to the strike; blue stations, located in the anti-strike direction (Martinique Island). Modified from Drouet et al. (2011) and Feuillet et al. (2011)

where, $\mathrm{V}_{\mathrm{S}}$ is the average $S$-wave velocity along the path (assumed to be $3.5 \mathrm{~km} / \mathrm{s}$ here), $Q\left(\mathrm{f}_{\mathrm{K}}\right)$ is the frequencydependent quality factor, $\gamma$ is the geometric spreading exponent, and $\mathrm{S}_{\mathrm{j}}\left(\mathrm{f}_{\mathrm{k}}\right)$ is the local site effect at each receiver $j$. 
Table 1 Characteristics of the eight selected events used in this study

\begin{tabular}{|c|c|c|c|c|c|}
\hline $\begin{array}{l}\text { Date } \\
\text { (yyyy-mm-dd) }\end{array}$ & $\begin{array}{l}\text { Time } \\
\text { (h:m:s. UTC) }\end{array}$ & $\begin{array}{l}\text { Location } \\
\text { (longitude/latitude) }\end{array}$ & $\begin{array}{l}\text { Depth } \\
(\mathrm{km})\end{array}$ & $\begin{array}{l}\text { Strike/dip/rake } \\
\left({ }^{\circ}\right)\end{array}$ & $\mathrm{Mw}$ \\
\hline 2004-11-21 & $11: 41: 08$ & $-61^{\circ} 30.12 / 15^{\circ} 45.88$ & 10.0 & $325 / 44 /-77$ & 6.3 \\
\hline 2005-02-14 & $18: 05: 59$ & $-62^{\circ} 24.36 / 15^{\circ} 48.36$ & 10.7 & $324 / 39 /-84$ & 5.8 \\
\hline 2004-11-21 & $18: 53: 03$ & $-61^{\circ} 33.67 / 15^{\circ} 50.05$ & 8.8 & $331 / 41 /-74$ & 5.3 \\
\hline $2004-11-27$ & $23: 44: 24$ & $-61^{\circ} 30.21 / 15^{\circ} 42.39$ & 9.2 & $289 / 41 /-160$ & 4.9 \\
\hline 2005-06-06 & 01:20:06 & $-61^{\circ} 32.08 / 15^{\circ} 49.10$ & 14.7 & $286 / 53 /-129$ & 4.8 \\
\hline 2005-01-29 & $14: 45: 00$ & $-62^{\circ} 25.12 / 15^{\circ} 48.02$ & 13.8 & - & 4.7 \\
\hline 2005-03-03 & $19: 24: 00$ & $-62^{\circ} 22.48 / 15^{\circ} 50.59$ & 13.4 & - & 3.9 \\
\hline $2005-02-23$ & 00:02:00 & $-62^{\circ} 20.24 / 15^{\circ} 50.59$ & 6.8 & - & 3.7 \\
\hline
\end{tabular}

The focal mechanisms of the five larger events were obtained by Feuillet et al. (2011). Date and localization are from Observatoire Volcanologique et Sismologique de Guadeloupe (OVSG), and the event magnitudes were calculated by Drouet et al. (2011)

In the log domain, Eq. (1) can be written as given in Eq. (4):

$y_{\mathrm{ijk}}=\mathrm{m}_{0_{\mathrm{i}}}+\log _{10}\left[\left(\frac{\left(2 \pi \mathrm{f}_{\mathrm{k}}\right)^{2}}{1+\left(\frac{\mathrm{f}_{\mathrm{k}}}{\mathrm{f}_{\mathrm{c}_{\mathrm{i}}}}\right)^{2}}\right)\right]-\gamma \log _{10}\left(\mathrm{r}_{\mathrm{ij}}\right)-\frac{\pi \mathrm{r}_{\mathrm{ij}} f_{\mathrm{K}}{ }^{1-\alpha}}{\log _{\mathrm{e}}(10) \mathrm{Q}_{\mathrm{o}} v_{\mathrm{S}}}+\mathrm{S}_{\mathrm{jk}}$

where, $y_{\mathrm{ijk}}=\log _{10}\left[\mathrm{~A}_{\mathrm{ijk}}\left(\mathrm{r}_{\mathrm{ij}}, \mathrm{f}_{\mathrm{k}}\right)\right], \mathrm{m}_{0_{\mathrm{i}}}=\log _{10}\left[\mathrm{M}_{\mathrm{O}_{\mathrm{i}}} \times \frac{2\left\langle\mathrm{R}_{\theta \phi}\right\rangle}{4 \pi \rho v_{\mathrm{S}} \mathrm{S}}\right]$, and $\left\langle\mathrm{R}_{\theta \phi}\right\rangle$ refers to the average source radiation pattern ( 0.55 for $S$-waves).

To compute the source term, we can rewrite Eq. (4) as Eq. (5):

$$
\begin{aligned}
& \log _{10}\left[\Omega_{\mathrm{i}}\left(\mathrm{f}_{\mathrm{k}}\right)\right]=\mathrm{m}_{\mathrm{oi}_{\mathrm{i}}}+\log _{10}\left[\left(\frac{\left(2 \pi \mathrm{f}_{\mathrm{k}}\right)^{2}}{1+\left(\frac{\mathrm{f}_{\mathrm{k}}}{\mathrm{f}_{\mathrm{c}_{\mathrm{i}}}}\right)^{2}}\right)\right] \\
& =\mathrm{y}_{\mathrm{ijk}}+\gamma \log _{10}\left(\mathrm{r}_{\mathrm{ij}}\right)+\frac{\pi \mathrm{r}_{\mathrm{ij}} \mathrm{f}_{\mathrm{k}}^{1-\alpha}}{\log _{\mathrm{e}}(10) \mathrm{Q}_{0} v_{s}}-\mathrm{S}_{\mathrm{jk}}
\end{aligned}
$$

$S$-wave Fourier spectra are computed from the time window that starts at the $S$-wave arrival time and ends where it includes $80 \%$ of the energy computed from the $S$-wave arrival time. The spectra were smoothed using the Konno and Ohmachi (1998) smoothing procedure, following Drouet et al. (2011). Then, we applied the correction described in Eq. (4), to remove propagation and site terms and to isolate the source spectra. We adopt the attenuation models determined by Drouet et al. (2011) (Table 2) to define the anelastic attenuation $\left(\mathrm{Q}_{\mathrm{o}}, \alpha\right)$ and geometric spreading $(\gamma)$ parameters. The station site terms are also taken from Drouet et al. (2011). The attenuation parameters differ for travel paths towards Guadeloupe and Martinique because the paths are crossing different regions and different portions of the crust. Indeed, the paths towards Martinique are longer than those towards Guadeloupe and sample a deeper part of the crust which leads to a lower attenuation.

The path- and site-corrected source spectra clearly fit the respective Brune's source spectral models for smallto-moderate events (Fig. 2a-e). The models developed by Drouet et al. (2011) explain these point-source spectra well, and there is no evident divergence between the various observations from different azimuthal station groups. Thus, for small-to-moderate earthquakes, directivity effects are not observed. This good fit also

Table 2 Attenuation parameters used in this study (Drouet et al. 2011)

\begin{tabular}{lllll}
\hline$\gamma$ & $\begin{array}{l}\text { Q01 } \\
\text { Guadeloupe data }\end{array}$ & $\begin{array}{l}\text { Q02 } \\
\text { Martinique data }\end{array}$ \\
\hline $1.058 \pm 0.001$ & $261 \pm 12$ & $0.16 \pm 0.01$ & $287 \pm 5$ & $0.35 \pm 0.01$ \\
\hline
\end{tabular}


a

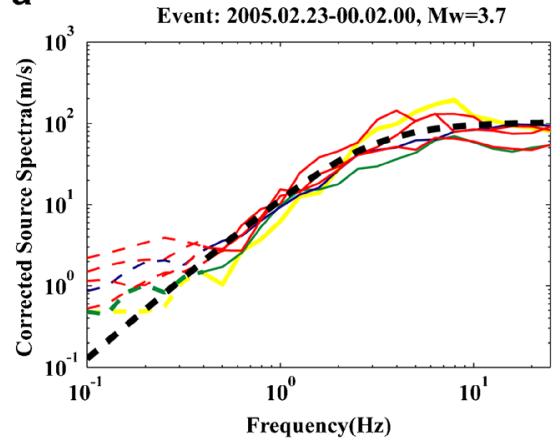

C

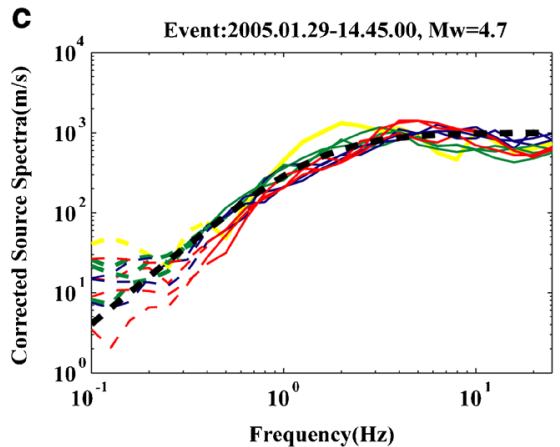

e

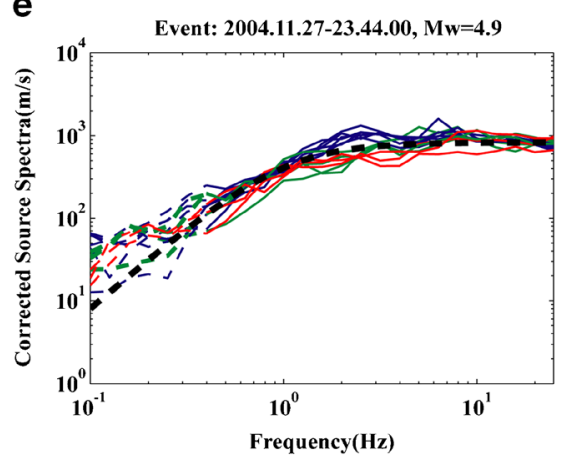

g

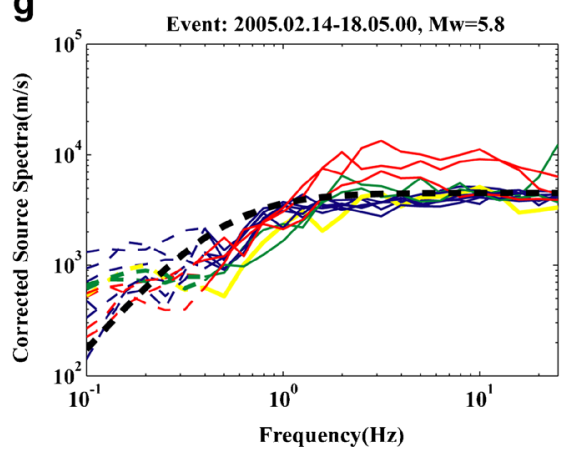

Fig. 2 Path- and site-corrected acceleration source spectra for different events, as indicated on the top of the frames (a) to (h). Colors refer to the stations classification (see Fig. 1 caption). To the low frequencies, the dashed spectra indicate where the signalto-noise ratio is poor (these data are not used in the analysis). The b

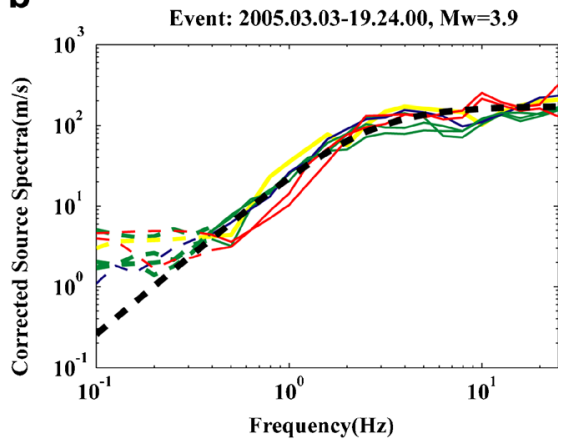

d

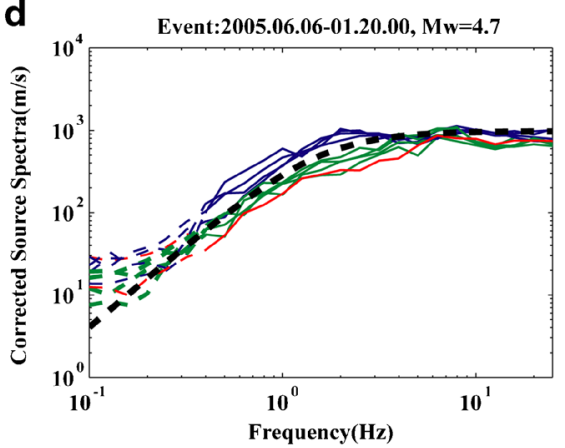

f

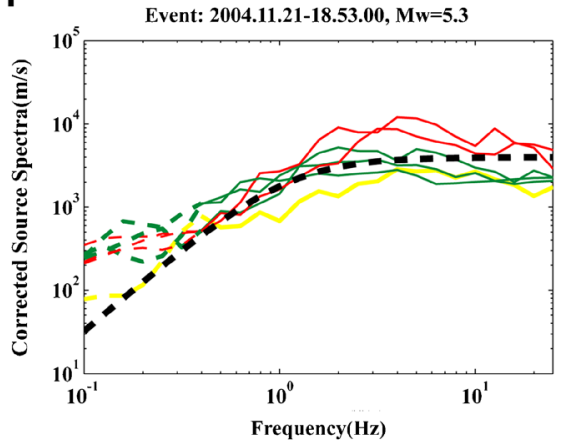

h

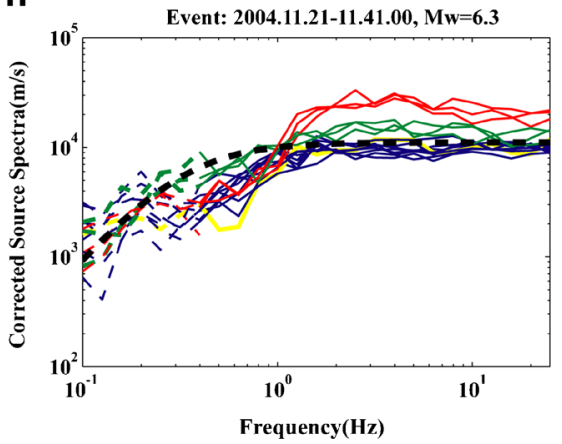

theoretical Brune's model calculated using the seismic moment and corner frequency of Drouet et al. (2011) is also shown (thick black dashed line). The applied path correction parameters are shown in Table 3, and the site correction parameters of each station are adopted from the work by Drouet et al. (2011) 
confirms the accuracy of regional attenuation parameters and the local site amplification derived by Drouet et al. (2011).

The records of the three largest shocks show different behavior (Fig. 2f-h). As the magnitude increases, significant source spectra azimuthal variations are observed. The height of the amplitude plateau is a function of the azimuth, which suggests a directivity effect. The main-shock event shows the clearest azimuthal variations. However, when trying to detect directivity effects, and thus any associated azimuthal dependency in the corrected source spectra, we need to first remove any possible radiation pattern influence.

\section{Do source radiation patterns explain the observed azimuthal variations?}

The radiation patterns refer to the angular dependency of the wave amplitudes from the seismic source, and they are thus a function of the take-off angles, focal mechanism, and the azimuth angle from the event to the station events.

To estimate the regional take-off angles, we adopt the widely used velocity model for the Les Saintes area (Dorel 1978). The main-shock centroid moment tensor focal mechanism was taken from Courboulex et al. (2010), and the radiation pattern coefficients were calculated using the equations given by Aki and Richards (2002).

The path and site-corrected source spectra are finally corrected from the radiation pattern effect using Eq. (6):

$m_{0_{\mathrm{i}}}=\log _{10}\left[\mathrm{M}_{0_{\mathrm{i}}} \times \frac{2 \frac{\left\langle\mathrm{R}_{\theta \varphi}\right\rangle}{\mathrm{R}(\theta, \varphi)}}{4 \pi \rho v_{s}{ }^{3}}\right]$

where $\mathrm{R}(\theta, \varphi)$ is the radiation pattern coefficient at takeoff angle $\varphi$ and azimuth angle $\theta$.

The corresponding parameters for each station are shown in Table 3. Here, we compute the radiation pattern coefficients for $S_{\mathrm{H}}$ and $S_{\mathrm{V}}$ waves and then take the geometric mean as the final radiation coefficients (RAD) since in the study, we have analyzed average Swave acceleration data.

These computed radiation patterns are only valid at low frequencies (Liu and Helmberger 1985). Indeed,
Table 3 Estimated radiation pattern (RAD), azimuth angle, and take-off angle of each station used in the main-shock analysis

\begin{tabular}{llrl}
\hline Station & Estimated RAD & Azimuth angle, $\theta$ & Take-off angle \\
\hline MADI & 0.43 & $156.51^{\circ}$ & $93.15^{\circ}$ \\
GBGA & 0.78 & $84.56^{\circ}$ & $110.85^{\circ}$ \\
ABFA & 0.32 & $-28.40^{\circ}$ & $105.52^{\circ}$ \\
PRFA & 0.37 & $-25.67^{\circ}$ & $106.90^{\circ}$ \\
IPTA & 0.50 & $16.87^{\circ}$ & $100.69^{\circ}$ \\
PIGA & 0.41 & $-21.02^{\circ}$ & $101.10^{\circ}$ \\
MESA & 0.45 & $20.80^{\circ}$ & $98.77^{\circ}$ \\
SFGA & 0.48 & $67.87^{\circ}$ & $98.60^{\circ}$ \\
SROA & 0.55 & $-6.84^{\circ}$ & $98.38^{\circ}$ \\
CGCA & 0.45 & $158.00^{\circ}$ & $94.07^{\circ}$ \\
MASP & 0.45 & $157.29^{\circ}$ & $94.24^{\circ}$ \\
MATR & 0.32 & $149.19^{\circ}$ & $93.83^{\circ}$ \\
MAZM & 0.40 & $154.34^{\circ}$ & $93.39^{\circ}$ \\
MAME & 0.35 & $151.28^{\circ}$ & $92.93^{\circ}$ \\
CGDI & 0.43 & $156.47^{\circ}$ & $93.09^{\circ}$ \\
MALA & 0.38 & $153.10^{\circ}$ & $93.39^{\circ}$ \\
MAMA & 0.35 & $151.28^{\circ}$ & $92.93^{\circ}$ \\
\hline
\end{tabular}

Takenaka et al. (2003) suggested that the frequencydependent distortion of the $S$-wave radiation pattern might be caused by the mixing and coupling of the horizontal $\left(S_{\mathrm{H}}\right)$ and vertical $\left(S_{\mathrm{V}}\right) S$-waves in the heterogeneous structure near the source region. By analyzing dense KiK-net array observations from the Tottori-Ken Seibu earthquake, Mw 6.6, and its aftershocks, Takemura et al. (2009) demonstrated the collapse of the $S$-wave front due to seismic-wave scattering in a heterogeneous structure and showed that the radiation pattern is more isotropic at high frequencies $(>2 \mathrm{~Hz})$. Castro et al.

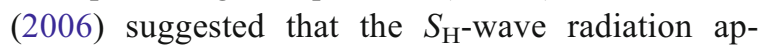
proaches the theoretical radiation only for frequencies below $0.5 \mathrm{~Hz}$. The evaluation of the frequency range at which radiation patterns start to become isotropic is thus still a debated issue.

Consequently, we evaluated the radiation pattern correction of the main-shock for two cases. First, we applied the correction within the whole frequency range ( 0.1 to $25 \mathrm{~Hz})$, then, only for the low frequency range (0.1 to $1 \mathrm{~Hz}$ ).

Figure 3 shows the raw source spectra for the mainshock as well as the source spectra corrected according to the radiation pattern. The radiation pattern correction 
a

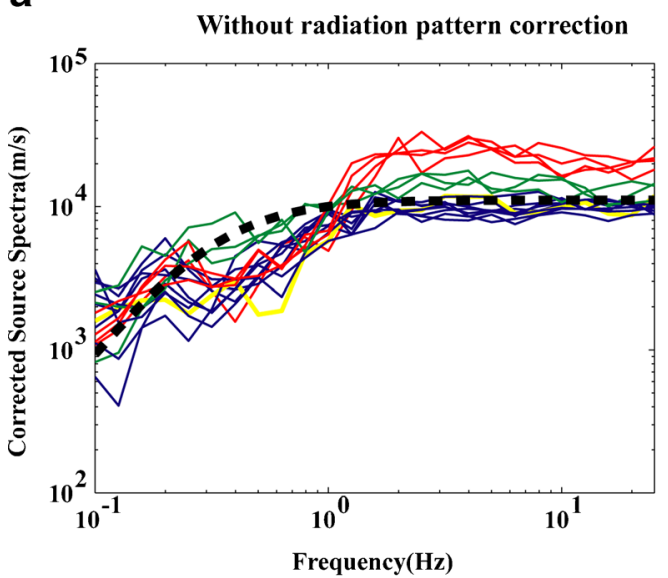

b

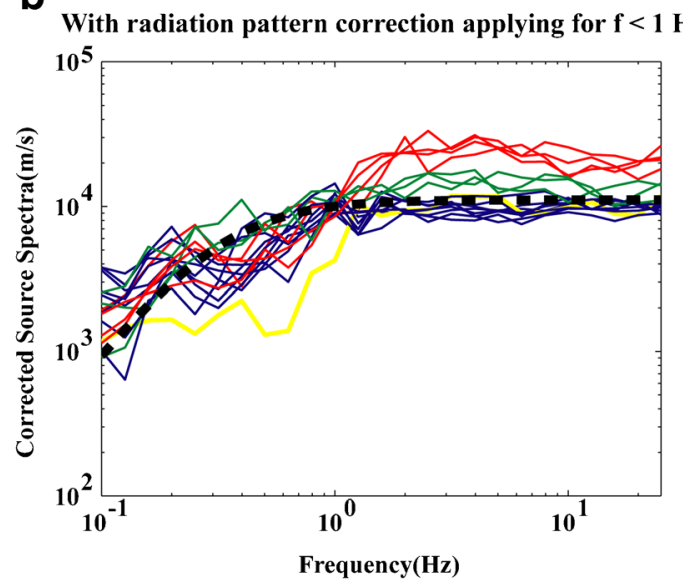

C

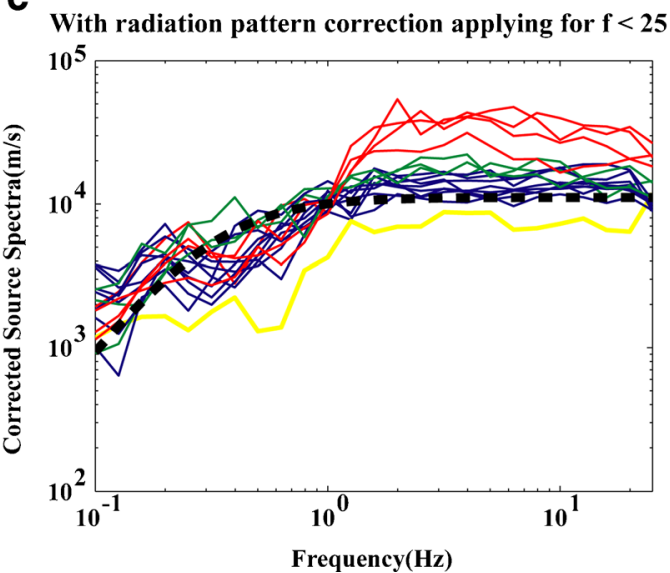

Fig. 3 Individual main-shock source spectra without radiation pattern correction (a) and with radiation pattern correction, as applied for frequencies $<1 \mathrm{~Hz}(\mathbf{b})$ and $<25 \mathrm{~Hz}$ (c). Colors refer to station classification (see Fig. 1 caption). The theoretical Brune's

highlights even more the azimuthal variations of the source spectra, especially when the correction is applied to the whole frequency band. These results confirm that directivity effects are the only physical phenomena that can explain the observed main-shock azimuthal variations.

\section{Results}

To analyze further these directivity effects, we use the slip and kinematic source model developed by Feuillet et al. (2011) (Fig. 1). This slip model is characterized by two main slip zones that are located 5 to $10 \mathrm{~km}$ to the model calculated using the seismic moment and corner frequency of Drouet et al. (2011) is also shown (thick black dashed line). The radiation pattern coefficients applied on each station are shown in Table 3

southeast and northwest of the hypocenter. Only a small portion of the total seismic moment was released in the hypocentral area. The largest and first rupture patch (southeast of the hypocenter) propagated towards the surface. The second patch rupture propagation to the northwest (towards the western part of Guadeloupe Island) is supported by the spectral amplitudes azimuthal variations shown in this study and by the analysis of Drouet et al. (2011). Indeed, the Drouet et al. (2011) analysis suggests a potential directivity effect to explain the azimuthal variation of the residuals and the large discrepancy between the residuals observed in Guadeloupe and Martinique. Moreover, Boatwright (2007) has shown that the aftershocks pattern is partly controlled by directivity effects. The fact that most of the 
aftershocks are located north of the main-shock epicenter then also suggests a directivity effect toward the northwest.

As the northwestern patch ruptures towards Guadeloupe (more or less along the strike direction), the stations located in Guadeloupe (Fig. 1, red and green triangles) are directive sites (especially the stations located along the strike). Stations sited in the Martinique area (Fig. 1, blue triangles) can be considered as antidirective sites for the first patch. Moreover, the southeastern patch ruptures towards the surface and the faults dip to the east, so we also consider the station located on Marie-Galante (Fig. 1, GBGA, yellow triangle) as an anti-directive site (Fig. 4a). To quantify these directivity effects, the mean values of the source spectra of each station group (Fig. 4b) were computed for the mainshock. As stated previously, many studies have shown that the radiation pattern becomes isotropic at high frequencies, and these results were obtained by applying the radiation pattern correction at low frequency only $(<1 \mathrm{~Hz})$.

Following the aftershock distribution, the inferred rupture direction is then consistent with the corrected source spectra behavior (Fig. 1): We observe the largest spectral amplitude at the directive sites, and especially at stations sited along the rupture direction. The lowest spectral levels are shown at both of the anti-directive sites, which confirm that the azimuthal dependence of the corrected spectra is caused by directivity effects.

To quantify these directivity effects, the means of the source spectra of each station group (Fig. 4) were computed for the main-shock. The frequency band below $0.5 \mathrm{~Hz}$ is dominated by noise for small events, and therefore the propagation and site-effect corrections were not calculated by Drouet et al. (2011). At intermediate frequencies (between 0.5 and $2 \mathrm{~Hz}$ ), both directive and anti-directive sites have a 'sag' in the source spectra (Fig. 4). At high frequencies $(>2 \mathrm{~Hz}$ ), the spectral plateaus obtained for the different station groups show large differences, and there is a ratio of about 2.0 to 2.5 between the directive and non-directive stations. These observations confirm the source models, which predict high directivity effects at high frequencies (Gallovic and Burjanek 2007). We computed the best fit for the source spectrum at the directive and antidirective sites according to the Brune's source spectrum with different corner frequencies. We observe that at directive sites, the fitted corner frequency is higher than the corner frequency at anti-directive sites (Fig. 4). We also note that the source spectral shapes obtained at

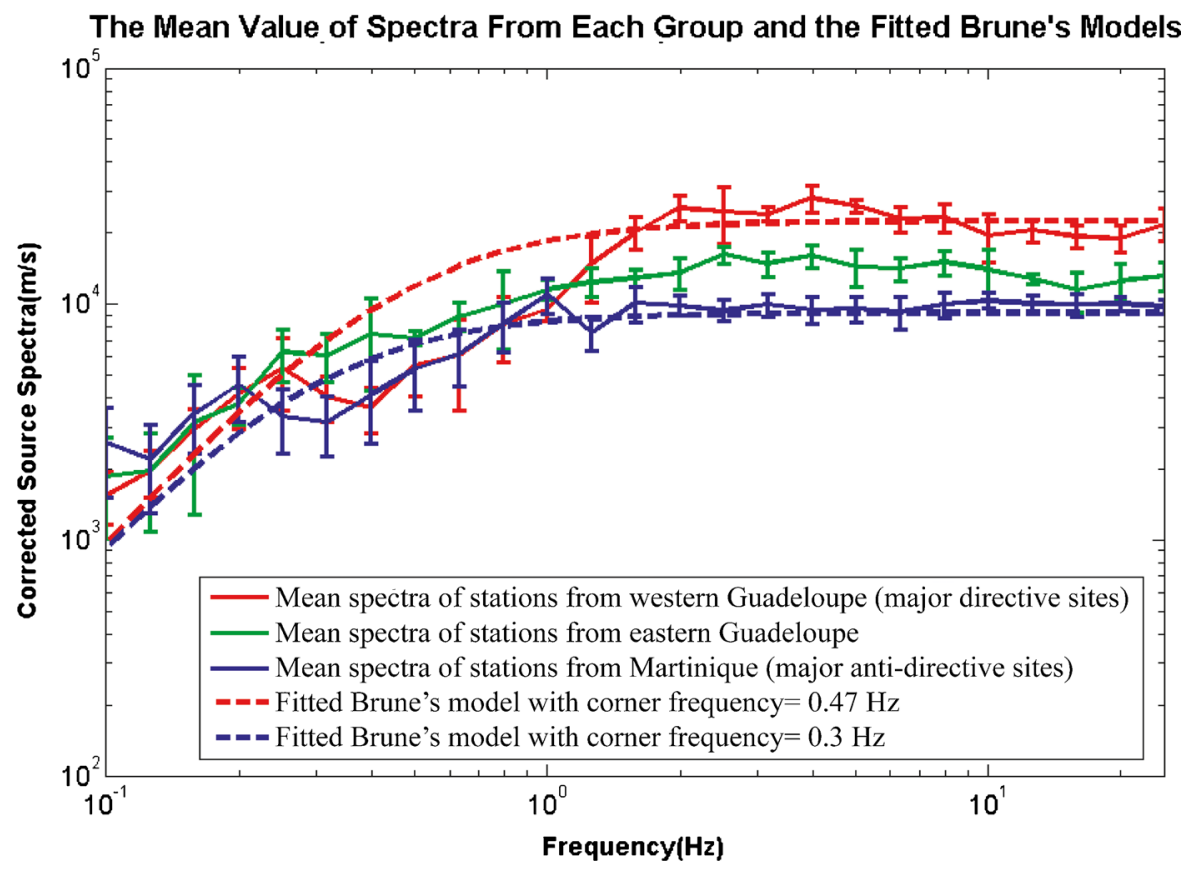

Fig. 4 Estimates of the mean spectra and error bars for the mainshock and for each group of stations (see legend). Two Brune's models with different corner frequencies that fit the records at the major directive and anti-directive sites are also shown (dashed lines). The figure shows how the directivity affects corner frequency and the spectra shapes 
directive and anti-directive sites cannot be explained by a Brune's source spectral shape anymore, probably because of the source complexity, and so the analysis of these corner frequencies in terms of stress drop or rupture velocity is difficult.

\section{Conclusion}

Applying appropriate corrections for path and site effects, and for radiation patterns, allows us to detect the impact of directivity effects on $S$-wave Fourier spectra. The point-source Brune's model explains the observed source spectra of small earthquakes $(\mathrm{Mw}<5.3)$, while the discrepancies between the observations and the predicted Brune's models caused by finite-source effects are significant for the main-shock and largest aftershocks (Mw, 6.3, 5.8, 5.3, respectively). Our study shows significant amplification (2.0- to 2.5-fold) of the acceleration spectral plateau due to directivity effects at high frequencies (2 to $25 \mathrm{~Hz}$ ). This evidence of highfrequency $(>1 \mathrm{~Hz})$ directivity effects contributes to the few observational studies that have been suggesting such effects (Boatwright et al. (2002), up to $1 \mathrm{~Hz}$ (Ameri et al. (2012)), and up to $2 \mathrm{~Hz}$ (Courboulex et al. (2013)).

Acknowledgments The comments of the associate editor and two anonymous reviewers significantly improved the submitted manuscript. We thank Ross Stein and Mathieu Causse for their useful suggestions and encouraging comments. This study originates from Yen-Shin's master's degree dissertation research project in Earthquake Engineering and Engineering Seismology (MEEES Consortium: www .meees.org). This study would not have been possible without the huge amount of work from the RAP network staff who provides the seismological community with high-quality accelerometric data. We especially thank MariePaule Bouin and our colleagues of the Observatoire Volcanologique et Sismologique de Guadeloupe for their support.

Open Access This article is distributed under the terms of the Creative Commons Attribution License which permits any use, distribution, and reproduction in any medium, provided the original author(s) and the source are credited.

\section{References}

Aki K, Richards PG (2002) Quantitative seismology. Univ Science Books

Ameri G, Gallovič F, Pacor F (2012) Complexity of the Mw 6.3 2009 L'Aquila (Central Italy) earthquake: 2. Broadband strong-motion modeling.
Bernard P, Herrero A (1994) Slip heterogeneity, body-wave spectra, and directivity of earthquake ruptures. Ann Geophys 37(6)

Boatwright J (2007) The persistence of directivity in small earthquakes. Bull Seismol Soc Am 97(6):1850-1861

Boatwright J, Choy GL, Seekins LC (2002) Regional estimates of radiated seismic energy. Bull Seismol Soc Am 92(4):12411255

Boore DM, Joyner WB (1989) The effect of directivity on the stress parameter determined from ground motion observations. Bull Seismol Soc Am 79(6):1984-1988

Castro RR, Franceschina G, Pacor F, Bindi D, Luzi L (2006) Analysis of the frequency dependence of the S-wave radiation pattern from local earthquakes in central Italy. Bull Seismol Soc Am 96(2):415-426

Courboulex F, Converset J, Balestra J, Delouis B (2010) Groundmotion simulations of the $2004 \mathrm{mw} 6.4$ les saintes, guadeloupe, earthquake using ten smaller events. Bull Seismol Soc Am 100(1):116-130

Courboulex F, Dujardin A, Vallée M, Delouis B, Sira C, Deschamps A, Honoré L, Thouvenot F (2013) High-frequency directivity effect for an Mw 4.1 earthquake, widely felt by the population in southeastern France. Bull Seismol Soc Am 103(6):3347-3353

Cultrera G, Pacor F, Franceschina G, Emolo A, Cocco M (2009) Directivity effects for moderate-magnitude earthquakes ( $\mathrm{Mw}$ 5.6-6.0) during the Umbria-Marche sequence, central Italy. Tectonophysics 476(1-2):110-120

Dorel J (1978) Sismicité et structure de l'arc des Petites Antilles et $\mathrm{du}$ bassin atlantique.

Drouet S, Bouin MP, Cotton F (2011) New moment magnitude scale, evidence of stress drop magnitude scaling and stochastic ground motion model for the French West Indies. Geophys J Int 187:1625-1644. doi:10.1111/j.1365-246X. 2011.05219.x

Feuillet N, Beauducel F, Jacques E, Tapponnier P, Delouis B, Bazin $\mathrm{S}$, Vallée M, King G (2011) The $\mathrm{Mw}=6.3$, November 21, 2004, Les Saintes earthquake (Guadeloupe): Tectonic setting, slip model and static stress changes. Journal of Geophysical Research: Solid Earth (1978-2012) 116 (B10)

Gallovic F, Burjanek J (2007) High frequency directivity in strong ground motion modeling methods. Ann Geophys 50:203-211

Haskell N (1964) Total energy and energy spectral density of elastic wave radiation from propagating faults. Bull Seismol Soc Am 54(6A):1811-1841

Konno K, Ohmachi T (1998) Ground-motion characteristics estimated from spectral ratio between horizontal and vertical components of microtremor. Bull Seismol Soc Am 88(1): 228-241

Liu HL, Helmberger DV (1985) The 23: 19 aftershock of the 15 October 1979 Imperial Valley earthquake: more evidence for an asperity. Bull Seismol Soc Am 75(3):689-708

Péquegnat C, Guéguen P, Hatzfeld D, Langlais M (2008) The French accelerometric network (RAP) and national data centre (RAP-NDC). Seismol Res Lett 79(1):79-89

Ruiz J, Baumont D, Bernard P, Berge-Thierry C (2011) Modelling directivity of strong ground motion with a fractal, $\mathrm{k}-2$, kinematic source model. Geophys J Int 186(1):226-244

Seekins LC, Boatwright J (2010) Rupture directivity of moderate earthquakes in Northern California. Bull Seismol Soc Am 100(3):1107-1119 
Somerville PG, Smith NF, Graves RW, Abrahamson NA (1997) Modification of empirical strong ground motion attenuation relations to include the amplitude and duration effects of rupture directivity. Seismol Res Lett 68(1):199-222

Spudich P, Chiou BSJ (2008) Directivity in NGA earthquake ground motions: analysis using isochrone theory. Earthquake Spectra 24:279

Takemura S, Furumura T, Saito T (2009) Distortion of the apparent $\mathrm{S}$-wave radiation pattern in the high-frequency wavefield: Tottori-Ken Seibu, Japan, earthquake of 2000. Geophys J Int 178(2):950-961
Takenaka H, Mamada Y, Futamure H (2003) Near-source effect on radiation pattern of high-frequency $\mathrm{S}$ waves: strong $\mathrm{SH}-\mathrm{SV}$ mixing observed from aftershocks of the 1997 Northwestern Kagoshima, Japan, earthquakes. Phys Earth Planet Inter 137(1):31-43

\section{Data and resources}

All accelerometric data are freely available at http://www-rap.obs. ujf-grenoble.fr/. 